\title{
Influence of Emotional Intelligence, Interpersonal Communication and Job Satisfaction on the Job Performance of Staff in Chevron Nigeria Limited, Warri, Delta State Nigeria
}

\author{
Jude J. Obiunu \\ Associate Professor, \\ Department of Guidance and Counselling, \\ Delta State University, Abraka, Nigeria \\ Jennifer O. Yalaju \\ Department of Guidance and Counselling, \\ Delta State University, Abraka, Nigeria
}

DOI: https://doi.org/10.36941/ajis-2020-0o7o

\section{Abstract}

This study investigated the influence of emotional intelligence, interpersonal communication and job satisfaction on the job performance of staff in Chevron Nigeria Limited, Warri. Four null hypotheses guided the study. The correlation research design was adopted in the study. A sample of 400 was selected by the researchers using simple random sampling technique. The instrument used for data collection was a validated and reliable questionnaire. Regression statistics was used to test the stated null hypotheses, at 0.05 level of significance. The findings in the study showed that the four null hypotheses were rejected which is an indication that there is a significant relationship between emotional intelligence, interpersonal communication, job satisfaction and job performance of staff in Chevron Nigeria Limited.

Keywords: Emotional Intelligence; Employees; Interpersonal Communication; Job Performance; Job Satisfaction

\section{Introduction}

Organizational success is driven by staff's commitment to get results the right way either by operating responsibly or executing with excellence. The goal of organizations is to maximize profit, which can be achieved if staffs are committed to their job. According to Clark (200o), improved performance will lead to positive result in the organization and their employees. It is a way to ensure economic and social development for the organization. Campbell (1990) defined performance as something done by an employee. To reach a goal or set of goals within a job, performance must be directed toward organizational goals.

Most workers are performing poorly and are less productive in their jobs because they lack certain skills that will enable them perform well on their jobs. Once there is effective job performance, productivity is bound to rise, and the organization will experience growth. There has been increase in research on how well an individual can perform in his or her job, and what can cause them not to perform well. Before now, lot of emphasis were placed on intelligence and technical 
know-how. However, it was thereafter noticed that other skills are involved which is what this study intends to unveil.

Salovey and Mayer (1990) defined emotional intelligence as the ability to recognize, evaluate, and express positive emotions. Emotional Intelligence has to do with understanding our feelings and that of others. In a study carried out by the Institute of Social and Emotional intelligence, it was found that success in life and at work can be influenced far more by individuals' social and emotional intelligence (SEQ) than by their cognitive intelligence (IQ). It has widely accepted that assessing human intelligence can predict performance over time. It is what helps an individual to focus, drive, make decisions, manage relationships and optimized to the fullest capacity in his or her personal and professional life.

Companies are being enlightened that encouraging Emotional intelligence is a vital component in any organization's management philosophy. Cooper (1997) in his research, show that individuals with higher emotional intelligence are likely to be more successful in life, work and are more likely to build stronger interpersonal relationships than those with low emotional intelligence. Individuals who have high emotional intelligence will control their emotions better, excel in jobs and can also unlock the potential of those around.

In every human relationship such as workplace, communication is something that must go on. It has been observed that good interpersonal communication will substantially contributes to effective organizational performance. Interpersonal communication among staffs may fail to serve its purpose when too many symbolic gestures are used, lack of language and listening skills. Scholars collectively have identified with and used interpersonal communication to describe their workplace performance. Good interpersonal communication should be encouraged at work as this is a means organizations mission and vision statement can be expressed.

As the job market continues to advance, the workforce and dramatic changes in technology will continue to leadto the creation of different kinds of jobs, and good interpersonal communication will enable one to solve problems, make critical decisions, communicate effectively and manage diverse working relationships.

Employees with low job satisfaction can negatively affect a company's productivity because they typically lack motivation and possess negative attitudes. Moorman (1993) noted that job satisfaction measures vary in the extent to which employees feels about their job. They are dissatisfied at their jobs when there is lack of career growth and advancement. A recent study by economists at the University of Warwick found out that satisfaction in a job led to $12 \%$ spike in productivity, while dissatisfied workers proved $10 \%$ less productive. So in other words, an employee who is satisfied with his or her job will yield positive performance that leads to productivity.

Researchers have identified numerous factors relating to job performance. Some of the studies are seen in the works of the following researchers. Mafuzah and Juraifa (2016) carried out a study on the relationship between emotional intelligence and Job Performance among Malaysian teachers. The Respondents were 212 teachers (33.5\% males and females 66.5\%) in 6 secondary schools in Kedah. The instrument for data collection was a 5-point Likert scale questionnaire. Reliability was done using Cronbach alpha. The study showed that emotional intelligence has a greater impact on teachers' job performance.

Kenneth, Chi-Sum , Guo-Hua andXiaoxuan (2008) did a study on the effects of emotional intelligence on job performance and life satisfaction. They argued that emotional intelligence is a major predictor of performance beyond General Mental Ability (GMA). A study by Wulandari (2014), on the influence of interpersonal communication on job performance revealed that the companies studied were able to nurture and sustain good interpersonal relationships among their employees through different interpersonal communication strategies.

The studies reviewed so far have shown that different scholars have conducted studies on job performance. And from the reviewed works, positive results were given in relation to the variables in this study. If staffs are emotionally intelligent and have good interpersonal communication, there is a tendency for them to emit positive results in their job performance. Employee that lacks these 
abilities might perform poorly. However, despite the numerous works in the reviewed literature, none to the best of the researches have been carried out among staff of Chevron Nigeria Limited in Warri, Delta State, Nigeria. It is on this premise that we carried out this study to determine the joint and relative influence of emotional intelligence, interpersonal communication and job satisfaction on the job performance of staff of Chevron Nigeria Limited, Warri, Delta State Nigeria. We hypothesized the following:

$\mathbf{H}_{\mathbf{o}} \mathbf{1}$ : There is no significant relationship between emotional intelligence, and job performance of staff in Chevron Nigeria Limited.

$\mathbf{H}_{\mathbf{o}}$ : : There is no significant relationship between interpersonal communication and job performance of staff in Chevron Nigeria Limited

$\mathbf{H}_{\mathbf{0}}$ : There is no significant relationship between job satisfaction and Job performance of staff in Chevron Nigeria Limited

$\mathbf{H}_{\mathbf{0} 4}$ : There is no significant relationship between Emotional intelligence, interpersonal communication, job satisfaction, gender, salary and Job Performance of staffin Chevron Nigeria Limited.

\section{Methods}

\subsection{Sample and Participants Selection}

The population of the study comprised all staff of Chevron Nigeria Limited in Warri, Delta State Nigeria, with a population size of 900 . We selected a total of 400 staff for the using simple random sampling technique. The 400 staff represents $45 \%$ of the total population. $45 \%$ was used to get the sample size because the value exceeds the minimum number recommended by Slovin. According to Slovin (1960), a minimum number of 277 as sample size is adequate for a population of 900 .

\subsection{Assessment and Measures}

The major instrument used in this study is a questionnaire designed to find out the influence of emotional Intelligence, interpersonal communication, and job performance. The Instrument consists of two (2) sections (section A and B). Section A contains bio-data information; this is used to elicit data based on gender and salary. Section B is divided into four (4) sub-scales measuring emotional intelligence, interpersonal communication, job satisfaction and job performance. The four (4) subsections contain forty five (45) items. Emotional intelligence scale has thirteen (13) items, interpersonal communication scale has ten (10) items, job satisfaction scale has twelve (12) items and job performance scale has ten (10) items respectively. For the purpose of scoring, Section B consist of questions constructed on a four-point item rating scale of Strongly Agree (SA), Agree (A), Disagree (D), and Strongly Disagree (SD) where $S A=4$ points, $A=3$ points, $D=2$ points, $S D=1$ point.

The instruments have face, content and construct validities. The face and content validity was done by expert's judgment. The construct validity was ensured through factor analysis. The factors were extracted using principal component analysis. An eigen value of 1.0 was used as criterion for the extraction. Thereafter they were rotated using varimax method. The total variance explained by the different scales include $78.48 \%$ for emotional intelligence scale (EIS), $52.38 \%$ for interpersonal communication scale (ICS), $51.44 \%$ for job performance scale (JPS) and $59.40 \%$ for job satisfaction Scale (JSS). In order to determine the reliability of the research instrument, the questionnaire was administered to thirty (30) staff of Nigerian Gas Company in Warri, who is not part of the study. The data was analyzed using Cronbach Alpha and a coefficient of $0.87,0.85,0.77$ and 0.76 was obtained for emotional intelligence scale, interpersonal communication, job performance, and job satisfaction respectively. The overall coefficient was 0.77 . 


\subsection{Procedure}

This study is a correlational survey that sought to establish the relationship among the variables of the study. The instruments were administered personally by the researchers to the staffs. The researchers were assisted by the human resource personnel in the organization where the study was conducted, and it ensured that there was no consultations among staff before ticking their responses.

\subsection{Data Analysis}

The data collected were analyzed in line with regression and multiple regressions, at 0.05 alpha level of signifcance. The Statistical Package for Social Sciences (SPSS) version 22 was used.

\subsection{Ethical Consideration}

Before administering the questionnaire on the respondents, the researchers obtained an informed consent from them after stating the purpose of the study. The respondents were also assured of the confidentiality of the information they will provide.

\section{Results}

3.1 $H_{\mathrm{o}}$ : There is no significant relationship between emotional intelligence and job performance of staff in Chevron Nigeria limited, Warri.

Table 1: Regression Analysis of Emotional Intelligence and Job Performance of Staff of Chevron Nigeria Limited, Warri

Model Summary

\begin{tabular}{|c|c|c|c|}
\hline $\mathbf{R}$ & R - Square & Adjusted R-Square & Std Error of the Estimate \\
\hline 0.289 & 0.083 & 0.081 & 4.93674 \\
\hline
\end{tabular}

\begin{tabular}{|l|c|c|c|c|c|}
\multicolumn{1}{|c|}{ ANOVA } & F & Sig \\
\hline Regression & Sum of Square & df & Mean Square & \multirow{3}{*}{36.236} & \multirow{2}{*}{0.000} \\
\hline Residual & 883.130 & 1 & 883.130 & 24.371 & \\
\hline Total & 9699.808 & 398 & & & \\
\hline
\end{tabular}

The result in table 1 showed the regression output of a linear relationship between emotional intelligence and job performance of staff of Chevron Nigeria Limited, Warri, with computed values of F-Value 36.236 and P-value of o.ooo. Testing the hypothesis at an alpha level of 0.05, the p-value of 0.000 was less than the alpha level of 0.05 . Hence, the null hypotheses which states that "There is no significance relationship between emotional intelligence and job performance among staff of Chevron Nigeria Limited, Warri" was rejected. The $\mathrm{R}^{2}$ adjusted value of 0.081 indicated that $8.1 \%$ of variance in job performance of staff of Chevron Nigeria Limited was accounted for by the emotional intelligence. 
3.2 $H_{0}$ : There is no significant relationship between interpersonal communication and job performance of staff of Chevron Nigeria limited, Warri.

Table 2: Regression Analysis of Interpersonal Communication and Job Performance of Staff of Chevron Nigeria Limited, Warri

Model Summary

\begin{tabular}{|c|c|c|c|}
\hline $\mathbf{R}$ & $\mathbf{R}-$ Square & Adjusted R Square & Std Error of the Estimate \\
\hline 0.286 & 0.082 & 0.080 & 4.94071 \\
\hline
\end{tabular}

ANOVA

\begin{tabular}{|l|c|c|c|c|c|}
\hline & Sum of Square & df & Mean Square & F & Sig \\
\hline Regression & 867.521 & 1 & 867.521 & & \\
\cline { 1 - 4 } Residual & 9715.417 & 398 & 24.411 & \multirow{2}{*}{0.00 .539} & \\
\hline Total & 10582.938 & 399 & & & \\
\hline
\end{tabular}

The result in table 2 showed the regression output of a linear relationship between interpersonal communication and job performance of staff of Chevron Nigeria Limited, Warri, had computed FValue of 35.539 and P-value of o.ooo. Testing the hypothesis at an alpha level of 0.05 , the p-value of o.ooo was less than the alpha level of 0.05. Therefore, the null hypotheses which states that "There is no significance relationship between interpersonal communication and job performance among staff of Chevron Nigeria Limited, Warri" was rejected. The $\mathrm{R}^{2}$ - adjusted value of $0.08 \mathrm{o}$ indicated that $8 \%$ of variance in job performance of staff of Chevron Nigeria Limited was accounted for by the interpersonal communication.

3.3 $H_{03}$ : There is no significant relationship between job satisfaction and Job Performance of Staff of Chevron Nigeria Limited, Warri

Table 3: Regression Analysis of job satisfaction and Job Performance of Staff of Chevron Nigeria Limited, Warri

\begin{tabular}{|c|c|c|c|}
\hline \multicolumn{4}{|c|}{ Model Summary } \\
\hline 0.485 & $\mathbf{R}-$ Square & Adjusted R-Square & Std Error of the Estimate \\
\hline
\end{tabular}

\begin{tabular}{|c|c|c|c|c|c|}
\multicolumn{7}{|c|}{ ANOVA } & F & Sig \\
\hline & Sum of Square & df & Mean Square & \multirow{3}{*}{122.634} & \multirow{2}{*}{0.000} \\
\hline Regression & 2492.788 & 1 & 2492.788 & & \\
\hline Residual & 8090.150 & 398 & 20.327 & & \\
\hline Total & 10582.938 & 399 & & & \\
\hline
\end{tabular}

The result in table 3 showed the regression output of a linear relationship between job satisfaction and job performance of staff of Chevron Nigeria Limited, Warri had computed F-Value of 122.634 and P-value of o.ooo. Testing the hypothesis at an alpha level of 0.05 , the p-value of 0.000 was less than the alpha level of 0.05 . Therefore, the null hypotheses which states that "There is no significance relationship between job satisfaction and job performance among staff of Chevron Nigeria Limited, Warri" was rejected. The $\mathrm{R}^{2}$ adjusted value of 0.234 indicated that $23.4 \%$ variance in job performance of staff of Chevron Nigeria Limited was accounted for by the job satisfaction. 
$H_{04}$ : There is no significant relationship emotional intelligence, interpersonal communication, job satisfaction and job performance of staff of Chevron Nigeria Limited, Warri

Table 4: Regression analysis of emotional intelligence, interpersonal Communication, Job Satisfaction and Job Performance of Staff of Chevron Nigeria Limited, Warri

Model Summary

\begin{tabular}{|c|c|c|c|}
\hline R & R - Square & Adjusted R- Square & Std Error of the Estimate \\
\hline 0.526 & 0.276 & 0.267 & 4.40840 \\
\hline
\end{tabular}

ANOVA

\begin{tabular}{|l|c|c|c|c|c|}
\hline & Sum of Square & df & Mean Square & F & Sig \\
\hline Regression & 2925.950 & 1 & 585.190 & & \\
\cline { 1 - 4 } Residual & 7656.988 & 394 & \multirow{3}{*}{30.112} & \multirow{2}{*}{0.000} \\
\cline { 1 - 4 } Total & 10582.938 & 399 & & & \\
\hline
\end{tabular}

The result in table 4 showed the regression output of a linear relationship between emotional intelligence, interpersonal communication, job satisfaction and job performance of staff of Chevron Nigeria Limited, Warri had computed F-Value of 30.112 and P-value of 0.000 . Testing the hypothesis at an alpha level of 0.05 , the p-value of 0.000 was less than the alpha level of 0.05 .Hence, the null hypothesis was rejected. The $\mathrm{R}^{2}$ - adjusted value of 0.267 indicated that $26.7 \%$ variance in job performance of staff of Chevron Nigeria Limited was accounted for by the emotional intelligence, interpersonal communication and job satisfaction.

\section{Discussion}

The result revealed that there is a positive significant relationship between emotional intelligence and job performance of staff of Chevron Nigeria Limited. Emotional intelligence is the ability of an individual to manage his emotions and that of others, to discriminate between different emotions and label them appropriately. The finding supports the study of George \& Brief (1996), whose finding revealed that job performance is a significant predictor of performance among employees. People that are emotionally intelligent produce win-win relationship and outcomes for themselves and others. They develop a magnetic field of emotional attraction around themselves and often have an ever increasing network of social relationship and emotional support structure unlike people that have low emotional intelligence. People with low emotional intelligence get involved sometimes in counterproductive emotional transactions that build around them a field of emotional repulsion which cause their social circles to become distance from them. The findings is also in line with Zahraei (2008) whose study found that employees' job performance is influenced by emotional intelligence. The studies of Law, Wong \& Xiaoxuan (2008) concur to the findings that emotional intelligence is a significant predictor of job performance.

The finding also indicated a positive significant relationshipbetween interpersonal communication and job performance of staff of Chevron Nigeria Limited. The finding showed that interpersonal communication aids cooperation among staff and support them to perform well. It improves communication and leads to a better understanding of any situation. The studies of Wulandari (2014) who noted that each company had their different interpersonal communication strategies with clients that would help to foster cooperation, and increase in their job performance further support the findings of this study. The study is in line with Pincus (1986) who revealed a positive significant relationship between interpersonal communication and job performance.

The finding further showed a positive significant relationship between job satisfaction and job performance among staff of Chevron Nigeria Limited, Warri. The findings supports the studies of Chandrasekar, (2011); Mohr and Puck (2007); Zohir(2007); Schneider, Hangers, Smith and Salikggio 
(2003); Harter, Schmidt and Hayes (2002); Evans and Jack (2003) found a positive significant correlation between job satisfaction and organization performance. The findings also should that there was a significant relationship among emotional intelligence, interpersonal communication, job satisfaction and job performance of staff of Chevron Nigeria Limited, Warri. The findings indicated that there was linear relationship among the variables. The result supported the studies of Malek (2000) who noted that individuals with higher emotional intelligence are more likely to resolve conflict effectively by using more collaborative styles of conflict resolution to manage their own emotions. The finding supports Pincus (1986) who showed that a significant relationship exists between interpersonal communication and job performance. The studies concur with Schneider, et al. (2003):Harter, et al. (2003), Evans and Jack (2003) who founded a positive correlation between job satisfaction and organizational performance.

The findings of the study are also in line with Burleson and Samter (2006) who stated that gender is a significant determinant of performance in the workplace.

\section{Conclusion and Recommendations}

The study concluded that emotional intelligence, interpersonal communication and job satisfaction had significant relationship with the job performance of staff of Chevron Nigeria Limited, Warri. On the basis of these findings, the following recommendations were made:

1. Counselling centers should be established in towns and villages where companies and industries are located.

2. Counsellors should be employed in the oil and gas industries and other sectors so that employees can be adequately guided on how to manage their emotions in the workplace for effective job performance.

3. All employees should be subjected to training and courses on emotional intelligence and interpersonal communication so they can have an in-depth knowledge of how their ability to manage emotions and communicate effectively will contribute to their productivity in the workplace.

4. The Counselling Association of Nigeria (CASSON) should organize programs, workshops, and seminar on emotional intelligence to guide the society.

\section{Limitation of the Study}

This study has contributed to the body of knowledge such that it established that job performance of staff in organizations can be influenced by emotional intelligence, interpersonal communication, and salary using data obtained from staff of Chevron Nigeria Limited, Warri. However, the researchers fear the fact that the population is a closed and homogenous population. This could introduce some limitations into the study. It is therefore hoped that a further studies with a more heterogenous population will address such limitations.

\section{Acknowledgements}

We acknowledge with gratitude, the efforts of our research assistant who helped to gather data and typeset the work. We are also grateful to the staff that participated in the study.

\section{References}

Adeyemo, D.A. (200o). Job involvement, career commitment, organizational commitment and job satisfaction of the Nigerian Police. A multiple regression analysis. Journal of Advance Studies in Education Management, 5(6), 35-41. 
Burleson, B.R.,\&Samter, W. (2006). Are there gender differences in the relationship between academic performance and social behavior? Human Communication Research, 19, 155-175.

Campbell, J.P. (1990). 'Modelling the performance prediction problem in industrial and organizational psychology.'In M. D. Dunnette\& L. M. Hough (Eds.), Handbook of Industrial and Organizational Psychology (pp. 687-732). Palo Alto, CA: Consulting Psychologists Press, Inc.

Chandrasekar, K. (2011). Workplace environment and its impact on organizational performance in public sector organizations. International Journal of Enterprise Computing and Business Systems, 1, 1-16.

Clark, S.C. (2000). Work/family border theory: A new theory of work/family balance. Human Relations, 53, 747770

Conte, J. (2005). A review and critique of emotional intelligence measures. Journal of Organizational Behavior, 26, 433-440.

Cooper, R.,\&Sawaf, A. (1997). Executive EQ: Emotional Intelligence in Cooper, Robert K.; Sawaf, Ayman (1998-o1o1). Executive EQ: Emotional Intelligence in Leadership and Organizations. Penguin.

Evans, J.R., \& Jack, E.P. (2003). Validating key results linkages in the Baldrige Performance Excellence Model. The Quality Management Journal, 10, 7-24.

George J.M., Brief A.P., (1996). Motivational agendas in the workplace: The effects of feelings on focus of attention and work motivation. Research in Organizational Behavior, 18, 75-109.

Harter, J.K., Schmidt, F.L., \& Hayes, T.L. (2002). Business-unit level relationship between employee satisfaction, employee engagement, and business outcomes: A meta-analysis. Journal of Applied Psychology, 87, $268-279$.

Harter, J.K., Schmidt, F.L., \& Keyes, C.L.M. (2003). Well-being in the workplace and its relationship to business outcomes, A Review of the Gallup Studies, Flourishing, The Positive Person and the Good Life, Chapter 9.

Kenneth, S.L., Chi-Sum, W., Guo-Hua, H.,\&Xiaoxuan, L. (2008). Effects of emotional intelligence on job performance and life satisfaction for the research and development scientists in China.AsianPacific Journal of Management, 25, 51-69.

Law, K. S., Wong, C., \&Song, L. J. (2008). The construct and criterion validity of emotional intelligence and its potential utility for management studies. Journal of Applied Psychology, 89(3), 483-496.

Mafuzah, M., \&Juraifa, J. (2016). Emotional intelligence and job performance: A study among Malaysian teachers. Procedia Economics and Finance, 35, 674-682.

Malek, M. (200o). Relationship between emotional intelligence and collaborative conflict resolution styles. Unpublished PhD. Thesis, United States International University, San Diego, CA.

Mohr, A. T., \& Puck, J. F. (2007). Role conflict, general manager job satisfaction and stress and the performance of international joint ventures. European Management Journal, 25, 25-35.

Moorman, R.H. (1993). The influence of cognitive and affective based job satisfaction measures on the relationship between satisfaction and organizational citizenship behavior. Human Relations, 6(6), 759-776.

Pincus, J. D.(1986), Communication Satisfaction, Job Satisfaction, and Job PerformanceJournal of Human Communication Research, 12 ( 3), 395-419.

Salovey, P., \& Mayer, J. (1990). Emotional intelligence. Imagination, Cognition and Personality, 9(3), $185^{-211 .}$

Schneider, B., Hanges, P. J., Smith, D.B., \& Salvaggio, A. N. (2003). Which comes first: Employee attitudes or organizational financial and market performance? Journal of Applied Psychology, 88, 836-851.

Wulandari, R. (2014). Enhancing job performance through effective interpersonal communication for foreign managers to Indonesian co-workers, Research Journal of Business Management,

Zahraei, S. H. (2008). Effect of emotional intelligence factors on Iranian Engineering and Manufacturing Marine Installation Company employees jab satisfaction and productivity. Unpublished M.A. Dissertation, Alzahra university, Tehran, Iran

Zohir, S. C. (2007). Role of Dhaka export processing zone: Employment and empowerment. Research Report, Bangladesh Institute of Development Studies, Dhaka, People's Republic of Bangladesh. 